\section{Cobertura vegetal arbórea em condomínios residenciais horizontais do bairro Santa Felicidade - Curitiba/Pr}

Resumo: O objetivo deste artigo foi levantar a quantidade e a fragmentação da cobertura vegetal arbórea em dezesseis condomínios do Bairro Santa Felicidade - Curitiba/Pr. Foram utilizados os parâmetros propostos por Valaski (2008): >25\% (positiva); entre 20\% e 25\% (mediana); e <20\% (negativa). Inspirouse no trabalho de Jim (1989) para classificar os fragmentos de vegetação em fragmentos interligados, fragmento(s) isolado(s) ou indivíduo(s) dispersos. Os resultados encontrados foram: avaliação positiva: 2; avaliação mediana: 1; avaliação negativa: 13 . Os resultados mostraram que nem sempre a propaganda utilizada para a venda destes empreendimentos condiz com a realidade e que o poder público não está trabalhando para a proteção e para o aumento da cobertura vegetal do bairro.

\section{Tree cover in horizontal residential condominiums in Santa Felicidade District - Curitiba/PR}

\begin{abstract}
The purpose of this article was to get the quantity and fragmentation of tree cover in sixteen condominiums in Santa Felicidade District - Curitiba/Pr. The parameters proposed by Valaski (2008) were used here. Through Jim's job (1989), the vegetation in connected fragments, isolated fragments or disperse individuals were classified. The results found were as follow: positive evaluation - 2; average evaluation - 1; negative evaluation - 13. The results showed that almost seldon the advertisement used for the sale of these businesses is compatible with reality and that the government is not working to protect and increase the vegetation cover in the district.
\end{abstract}

*Mestre em Geografia Física pela Universidade Federal do Paraná e Doutoranda do Programa de Pósgraduação em Geografia Física na Universidade Federal do Paraná.

**Professor Associado I do Departamento de Geografia - UFPR

Palavras-chave: Arborização Urbana; Qualidade Ambiental Urbana; Marketing.

Key-words: Urban arborization; Urban environmental quality; Marketing. 


\section{Introdução}

Uma forma de ocupação do solo urbano que vem se propagando nas cidades brasileiras é o condomínio residencial horizontal. Os trabalhos acadêmicos consultados para a realização deste trabalho, que tiveram como objeto de estudo este tipo de empreendimento, foram desenvolvidos destacando principalmente os aspectos econômicos, sociais e culturais. A temática ambiental ou os elementos do meio físico, como vegetação, solo, geomorfologia e hidrografia, são temáticas que não figuram como as mais relevantes neste tipo de estudo.

Diferentemente da ocupação que vai ocorrendo lote a lote, com a expansão paulatina da zona urbana, espera-se que na implantação de um condomínio residencial horizontal a cobertura vegetal, especialmente a arbórea, seja levada em consideração, constituindo-se 0 principal elemento de composição paisagística pensando-se, entre outros, na possibilidade de um maior contato com a natureza, argumento amplamente utilizado pelas construtoras no momento da venda das residências em condomínios.

Partindo do pressuposto de que os condomínios residenciais horizontais ocupam grandes áreas que podem ser planejadas como um todo, e de que a propaganda os apresenta como sendo lugares onde se pode ter maior contato com a natureza, este trabalho objetivou analisar a quantidade e a fragmentação da cobertura vegetal arbórea presente em condomínios. Foram escolhidos dezesseis condomínios localizados no bairro Santa Felicidade - Curitiba/Pr.

\section{Referencial Teórico}

\section{Condomínios Residenciais Horizontais}

A análise da paisagem urbana na atualidade nos remete a observar um modelo de moradia que vem se tornando cada vez mais frequente nas cidades brasileiras: os condomínios residenciais horizontais.

Os condomínios residenciais horizontais ou "condomínios exclusivos" começaram a surgir nas grandes cidades brasileiras na década de 1970 (O'NEILL, 1986). Em 1975 foi inaugurado em São Paulo o AlphaVille, condomínio de uso misto (residencial, comercial e de serviços). Posteriormente, o AlphaVille, que se tornou um modelo de condomínio horizontal, foi implantado em outras grandes cidades como Campinas (1997), Belo Horizonte (1998), Curitiba (2000), Goiânia (2002), dentre outras e também em Portugal (DACANAL, 2004; ALBUQUERQUE et al., 2003).

Os condomínios de uso exclusivamente residencial são os mais comumente construídos nas cidades brasileiras, sendo mais freqüentes os condomínios horizontais. Esses condomínios podem ser encontrados tanto dentro da malha urbana (pequeno e médio porte) quanto na periferia (grande porte) (BECKER, 2005).

As possibilidades de uma vida mais segura, em contato com a natureza e em residências de alto padrão, são apelos veiculados pelas construtoras no momento da venda destes empreendimentos. Segundo Caldeira (2000, p.265) a definição de condomínios colocada pelo marketing os compara a ilhas: "os anúncios apresentam a imagem de ilhas para as quais se pode retornar todos os dias para escapar da cidade e para encontrar um mundo exclusivo de prazer entre iguais".

De acordo com Silva (2003) a força da publicidade tem sido um elemento importante para a 
formação dessa nova cultura habitacional. Certamente que os encantos da publicidade têm força significativa no imaginário dos indivíduos que, ao se sentirem reféns de uma situação caótica, encontram um refúgio nos anúncios que "vendem" um mundo aprazível, aconchegante, próximo à natureza e longe dessa "confusão" da cidade. A ideia é a de que as imagens publicitárias levam ao imaginário dos indivíduos outro tempo, outro espaço. As pessoas se vêem envolvidas por imagens que evidenciam uma vivência em constante harmonia, felicidade, pessoas convivendo num ambiente agradável, tranqüilo, silencioso, próximo à natureza. 0 mundo "lá fora" faz parte da vida do "outro".

Delicato (2004) coloca que, embora em escala menor, assim como a questão da segurança, a preocupação ecológica é incorporada a um ideal de moradia que renega a cidade nos moldes atuais. Os empreendedores exploram as deficiências da cidade e apostam em vender qualidade de vida associando valores ecológicos aos condomínios lançados no mercado imobiliário.

A questão ambiental e de marketing que aparece vinculada a este tipo de empreendimento imobiliário também é comentada por Dacanal (2004, p. 79):

"As áreas verdes parecem ser o principal elemento que estimula a comercialização de um condomínio horizontal, (...) o marketing empregado nas vendas das unidades residenciais utiliza o elemento vegetação como um diferencial que leva à melhoria da qualidade ambiental e de vida de habitantes de condomínios horizontais em relação aos outros bairros."

Assim, os condomínios residenciais horizontais apresentam-se como um lugar ideal para se viver, uma opção de fuga do caos urbano e de todos os problemas a ele associados, tanto os de ordem social e econômica, quanto ambiental.

\section{Vegetação urbana}

Na dinâmica da urbanização é perceptível, em muitos casos, a falta de importância que é atribuída à questão da presença de vegetação nas cidades. São valorizados os imóveis, o estilo arquitetônico, a localização, entre outros fatores, porém, não são feitas análises acerca da necessidade de se deixar no terreno espaços livres para o plantio de vegetação.

Segundo Nucci $(2001,2008)$, a cobertura vegetal é um atributo muito importante para 0 desenvolvimento das cidades. A maioria das pessoas relaciona a vegetação a uma função de satisfação psicológica e cultural. Porém, Monteiro (1976¹, apud NUCCI, 2001, 2008), na década de 1970, evidenciou que o homem tem necessidade de vegetação que vai além do valor sentimental e estético.

De acordo com Nucci (2001, p.60), a vegetação no meio urbano pode trazer muitos benefícios ao ser humano:

(...) estabilização de superfícies por meio da fixação do solo pelas raízes das plantas; obstáculo contra o vento; proteção da qualidade da água, pois impede que substâncias poluentes escorram para os rios; filtração do ar, diminuindo a poeira em suspensão; equilíbrio do índice de umidade do ar; redução do barulho; proteção das nascentes e dos mananciais; abrigo à fauna; organização e composição de espaços no desenvolvimento de atividades humanas; é um elemento de valorização visual e ornamental; estabilização da temperatura do ar; segurança das calçadas como acompanhamento viário; contato com a natureza colaborando com a saúde
1 MONTEIRO, C. A. F. Teoria e clima urbano. São Paulo, IGEOG/USP, 1976, 181p.

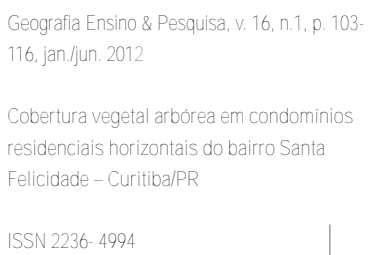


2 Oke, T.R. 1973. City size and the urban heat island. Atmospheric Environment, 7, 769-779.
Geografia Ensino \& Pesquisa, v. 16, n.1, p. 103 116, jan.jun. 2012

Cobertura vegetal arbórea em condomínios residenciais horizontais do bairro Santa Felicidade - Curitiba/PR psíquica do homem; recreação; contraste de texturas, mistérios e riquezas de detalhes; árvores decíduas lembrariam ao homem as mudanças de estação; quebra da monotonia das cidades, cores relaxantes, renovação espiritual; consumo de vegetais e frutas frescas; estabelecimento de uma escala intermediária entre a humana e a construída; caracterização e sinalização de espaços, evocando sua história.

A existência de vegetação nos centros urbanos, tais como parques, praças e ruas arborizadas proporcionam uma sensação de bem estar aos usuários destes espaços. As plantas utilizadas no paisagismo urbano, tão importantes na caracterização ambiental destas áreas, promovem inúmeros benefícios estéticos e funcionais ao homem.

De acordo com Hough (1998) a evolução dos parques públicos nas crescentes cidades da Europa e dos Estados Unidos no século XX, ganhou impulso com o movimento romântico. Foram criados com a convicção de que a natureza deveria mudar-se para a cidade para melhorar a saúde das pessoas, proporcionando espaços para exercício e relaxamento. Achavase que a oportunidade de contemplar a natureza melhoraria os costumes morais. Uma nova preocupação pela estética da paisagem natural levou à convicção de que os parques melhorariam a aparência das cidades.

Para Mascaró (1996, p.67), "a árvore é a forma vegetal mais característica na paisagem urbana (...) Considerada hoje mais na sua condição de ser vivo do que de objeto de uma composição arquitetônica, contribui para obter uma ambiência urbana agradável." A influência da vegetação na temperatura do ar relaciona-se com o controle da radiação solar, do vento e da umidade do ar. Sob um grupamento de árvores a temperatura do ar é $3^{\circ} \mathrm{C}$ a $4^{\circ} \mathrm{C}$ menor que nas áreas expostas à radiação solar. A autora complementa afirmando que a vegetação também reduz a incidência da precipitação sobre o solo e altera a concentração da umidade na atmosfera e nas superfícies adjacentes. Outro benefício é o do sombreamento causado pela vegetação, que desempenha importante papel na caracterização de microclimas urbanos, melhorando as condições ambientais adversas e o conforto humano.

Os benefícios da vegetação são comprovados cientificamente, entretanto, não há um índice ideal de cobertura vegetal para as áreas urbanas.

A Sociedade Brasileira de Arborização Urbana (SBAU) solicita o desenvolvimento de "(...) estudos e pesquisas com o objetivo de definir parâmetros que permitam relacionar e quantificar a necessidade mínima de área verde por habitante" (SBAU, 2010).

Em uma busca nas proposições da Organização Mundial da Saúde, com base em trabalho de Barton e Tsourou (2000), não foi encontrada qualquer sugestão de índices relacionados com 0 verde urbano.

Todavia, podem ser encontradas algumas sugestões no aspecto quantitativo em relação ao verde urbano.

Oke (1973² apud LOMBARDO, 1985) afirma que um índice de cobertura vegetal na faixa de 30\% seria o recomendável para proporcionar um adequado balanço térmico em áreas urbanas, sendo que um índice de arborização inferior a 5\% determina características semelhantes à de um deserto.

Para Sukopp e Werner (1991) a cidade poderia edificar ou pavimentar, aproximadamente, somente dois terços da superfície de sua área central, e que os 33\% restantes deveriam ser permeáveis, não edificados e cobertos por vegetação com ampla conexão com a zona rural.

Em Attwell (2000) encontram-se sugestões de índices para a cidade de Munique, na 
Alemanha, que indicam para as áreas residenciais de baixa verticalização a meta de $50 \%$ de cobertura vegetal, sendo $25 \%$ de cobertura de árvores e arbustos, para as áreas ocupadas por complexo de apartamentos, o valor de 30\% de cobertura vegetal, sendo 15\% para árvores e arbustos e para as áreas industriais $20 \%$ de cobertura vegetal com $10 \%$ para árvores e arbustos.

Quanto à distribuição espacial do verde nas cidades, Jim (1989), estudando Hong Kong, apresentou uma classificação dos diferentes tipos de manchas de cobertura vegetal arbórea, considerando-se a fragmentação ou continuidade da cobertura vegetal (FIGURA 1)

Jim (op cit.) propôs uma classificação para as formas espaciais de cobertura vegetal arbórea. No entanto, o mapeamento e a classificação do porte da vegetação também são importantes, pois "a quantidade e a distribuição de suas categorias, ou seja, herbácea, arbustiva ou arbórea, estão relacionadas com conforto térmico, com a qualidade do ar, escoamento superficial, uso pela população, etc." (MOURA e NUCCI, 2005).

Hough (1998) comenta que do ponto de vista climático em uma cidade, uma distribuição mais uniforme de pequenos espaços arborizados é mais efetiva que a concentração de poucos lugares grandes, estes necessitando ser complementados com um grande número de pequenos parques através da área construída para facilitar o deslocamento horizontal das massas de ar de diferentes temperaturas.

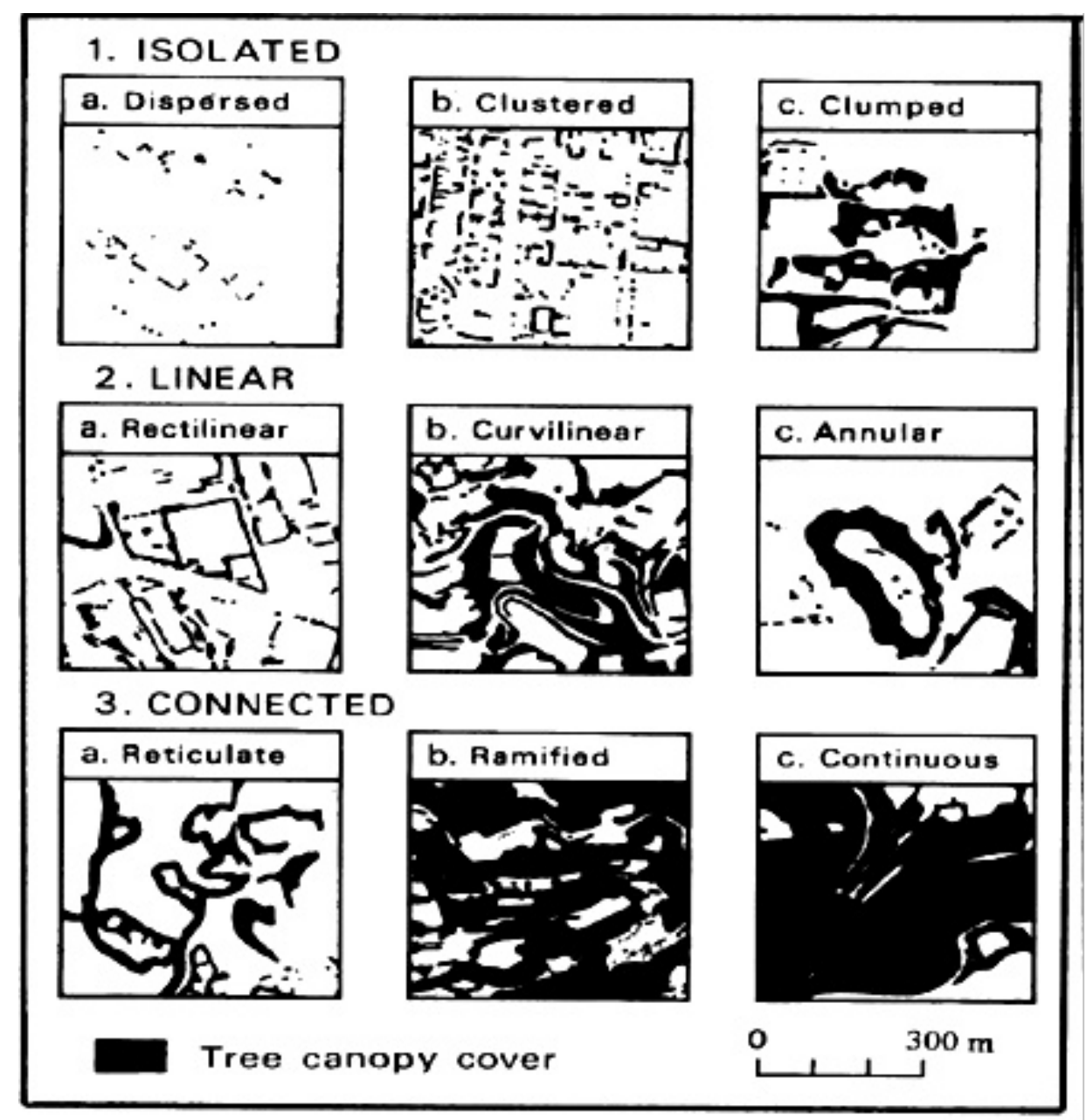

ra 1 - esquema de classificação da distribuição espacial da cobertura vegetal Fonte: jim (1989
Geografia Ensino \& Pesquisa, v. 16, n.1, p. 103116, jan.jjun. 2012

Cobertura vegetal arbórea em condomínios residenciais horizontais do bairro Santa Felicidade - Curitiba/PR 


\section{Localização e caracterização da área de estudo}

O bairro de Santa Felicidade está localizado na porção norte de Curitiba e ocupa uma área de 12,27 km2, que corresponde a 2,85\% da área total do município (FIGURA 2). 0 bairro dista do ponto zero de Curitiba, aproximadamente, $7 \mathrm{~km}$.

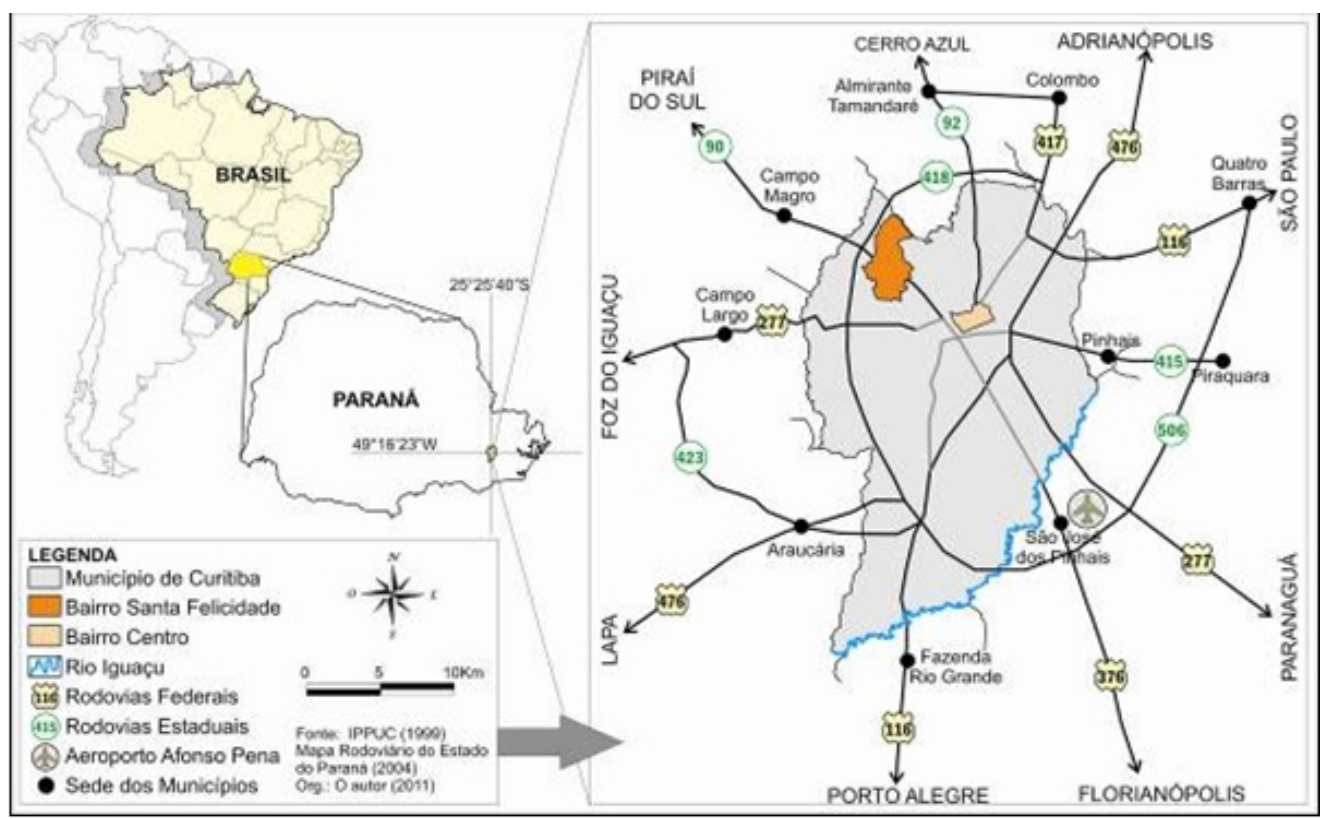

Figura 2 - Localização do Bairro Santa Felicidade - Curitiba/PR

A ocupação mais intensiva da região ocorreu a partir de 1878, com a chegada dos imigrantes italianos. Em 1891 era inaugurada a primeira igreja do bairro e em 1902 já estavam instaladas na colônia mais de 200 famílias dedicadas ao cultivo de milho, vinhedos e hortaliças, à criação de galinhas e gado e às atividades comerciais e de prestação de serviços, como armazéns e ferrarias, bem como a fabricação de queijos e vinhos. Em 1916 é criado o Distrito Judiciário tendo como limites: a leste, o rio Barigui; a oeste, o rio Passaúna; ao norte, as estradas do Taboão e do Juruquy e, ao sul, as Colônias Órleans e Santo Ignácio (IPPUC, 2008).

Atualmente o bairro é um importante ponto turístico da cidade devido à gastronomia, com grande quantidade de restaurantes de cozinha italiana, além de ter muitas vinícolas e lojas de artesanato.

O bairro de Santa Felicidade ainda apresenta uma paisagem bastante diversificada, sendo possível encontrar chácaras e fragmentos de vegetação nativa, bem como áreas residenciais e com comércio intenso (FIGURAS 3 e 4). Levantamento realizado por Moura e Nucci (2010) contabilizou para o bairro de Santa Felicidade, aproximadamente, um total de 42\% de cobertura vegetal (30\% arbórea, 2\% arbustiva e 10\% herbácea), ocupando quase em sua totalidade espaços de uso privado. 


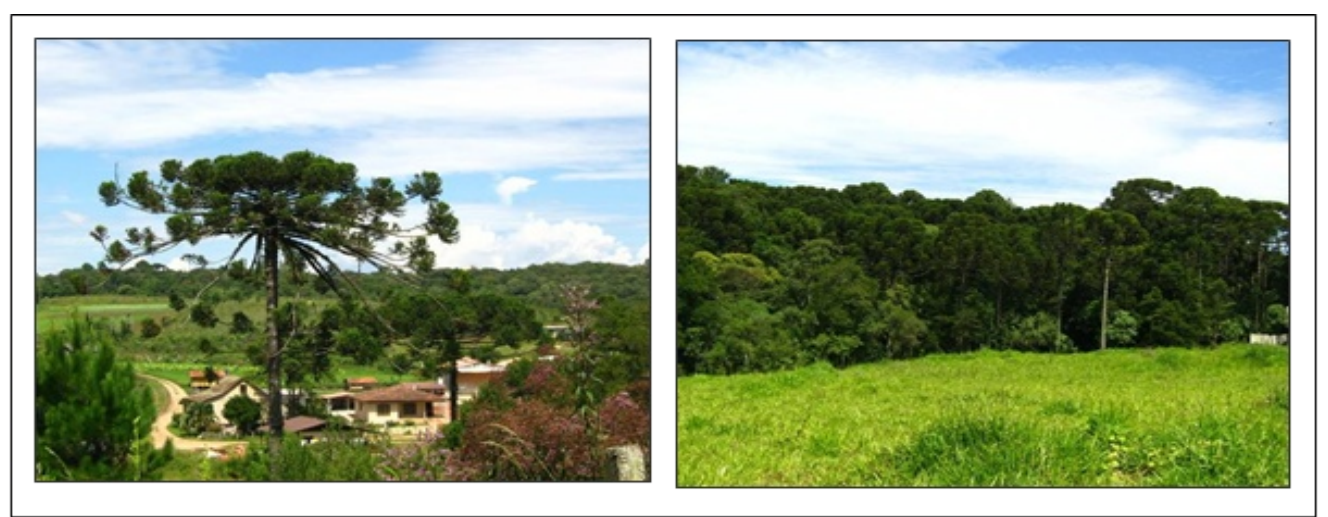

Figura 03 - Chácaras e áreas com vegetação no Bairro Santa Felicidade Fonte: Valaski (2008)

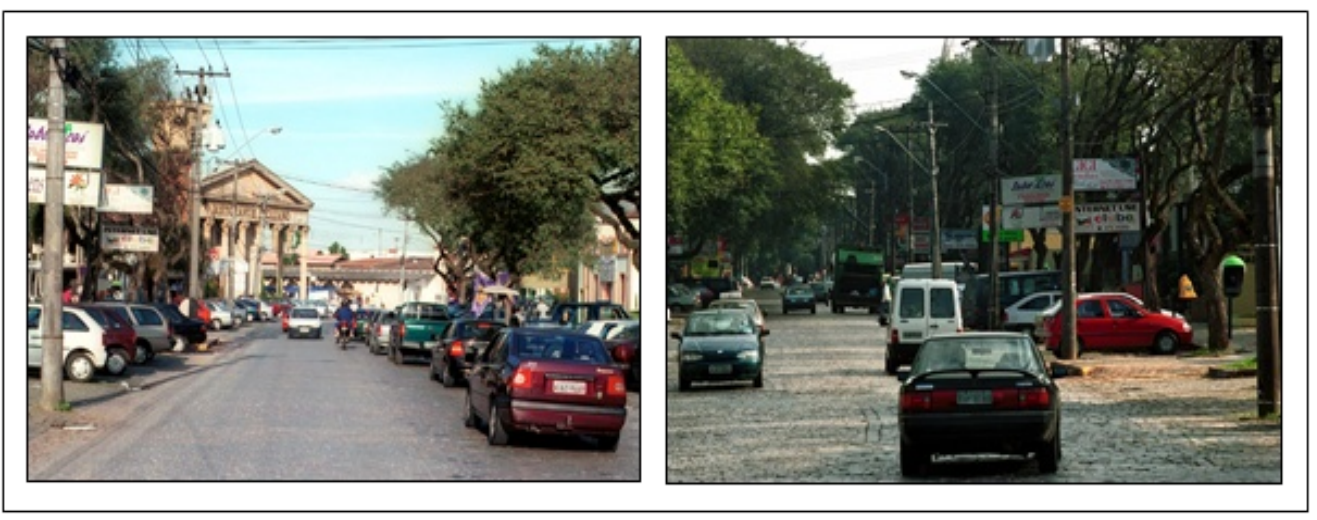

Figura 04 - Avenida Manoel Ribas, na parte central do bairro Fonte: IPPUC (2008)

A valorização do bairro no mercado imobiliário vem promovendo a venda de muitas das grandes propriedades particulares, que são então desmatadas e destinadas à construção civil, para moradias, notadamente os condomínios de alto padrão, e empresas, levando à diminuiçã̃o e fragmentação da cobertura vegetal, à exposição e impermeabilização do solo, ocorrendo assim uma queda da qualidade ambiental (MOURA e NUCCI, 2010).

\section{Metodologia}

O procedimento adotado inicialmente foi a seleção dos condomínios a serem usados como estudo de caso. Para isto, foram utilizados o mapa de localização dos condomínios residenciais horizontais em Santa Felicidade, elaborado por Valaski (2008) (FIGURA 5) e imagens de satélite Google Earth, datadas de 21/05/2009. Segundo Valaski (2008), o bairro possuía 57 condomínios com casas separadas já implantados, 10 condomínios com sobrados geminados e 9 em construção.

Como critério para a seleção dos condomínios a serem avaliados foi utilizado o número de residências: igual ou superior a 9. Foram selecionados 16 condomínios (FIGURA 6).

Para 0 cálculo da área e da cobertura vegetal arbórea (C.V.A.) foi utilizado o software Global Mapper 12, sendo possível calcular, posteriormente, o percentual de cobertura vegetal arbórea de cada condomínio. O cálculo de C.V.A. dos condomínios foi feito levando-se em

Geografia Ensino \& Pesquisa, v. 16, n.1, p. 103116, jan.jjun. 2012

Cobertura vegetal arbórea em condomínios residenciais horizontais do bairro Santa Felicidade - Curitiba/PR

ISSN 2236- 4994 
consideração todas as manchas de copas de árvores que puderam ser identificadas na imagem de satélite, na escala de, aproximadamente, 1:3.000.

A avaliação final dos condomínios foi realizada de acordo com a proposta de método de avaliação da qualidade ambiental em condomínios residenciais horizontais desenvolvida por Valaski (2008). Neste método a cobertura vegetal arbórea (C.V.A.) é caracterizada como um dos atributos que tem importante relação com a qualidade ambiental.

Os parâmetros utilizados no método desenvolvido por Valaski (2008) para avaliar a cobertura vegetal arbórea estão divididos em três partes: >25\%; entre 20\% e 25\%; e <20\%. Um índice de C.V.A. superior a 25\% tem uma avaliação denominada de positiva; índices entre 20\% e $25 \%$ são considerados como medianos; e valores inferiores a $20 \%$ são considerados negativos. Esses valores estão baseados nas sugestões de índices para a cidade de Munique (Alemanha), que indicam para as áreas residenciais de baixa verticalização a meta de 50\% de cobertura vegetal, sendo $25 \%$ de cobertura de árvores e arbustos. (ATTWELL, 2000)

Além do percentual de C.V.A. de cada condomínio fez-se uma caracterização desta cobertura, com inspiração do trabalho de Jim (1989), classificando-a em: fragmentos interligados, fragmento(s) isolado(s) ou indivíduo(s) isolados ou dispersos.

Geografia Ensino \& Pesquisa, v. 16, n.1, p. 103116, jan.jun. 2012

Cobertura vegetal arbórea em condomínios residenciais horizontais do bairro Santa Felicidade - Curitiba/PR

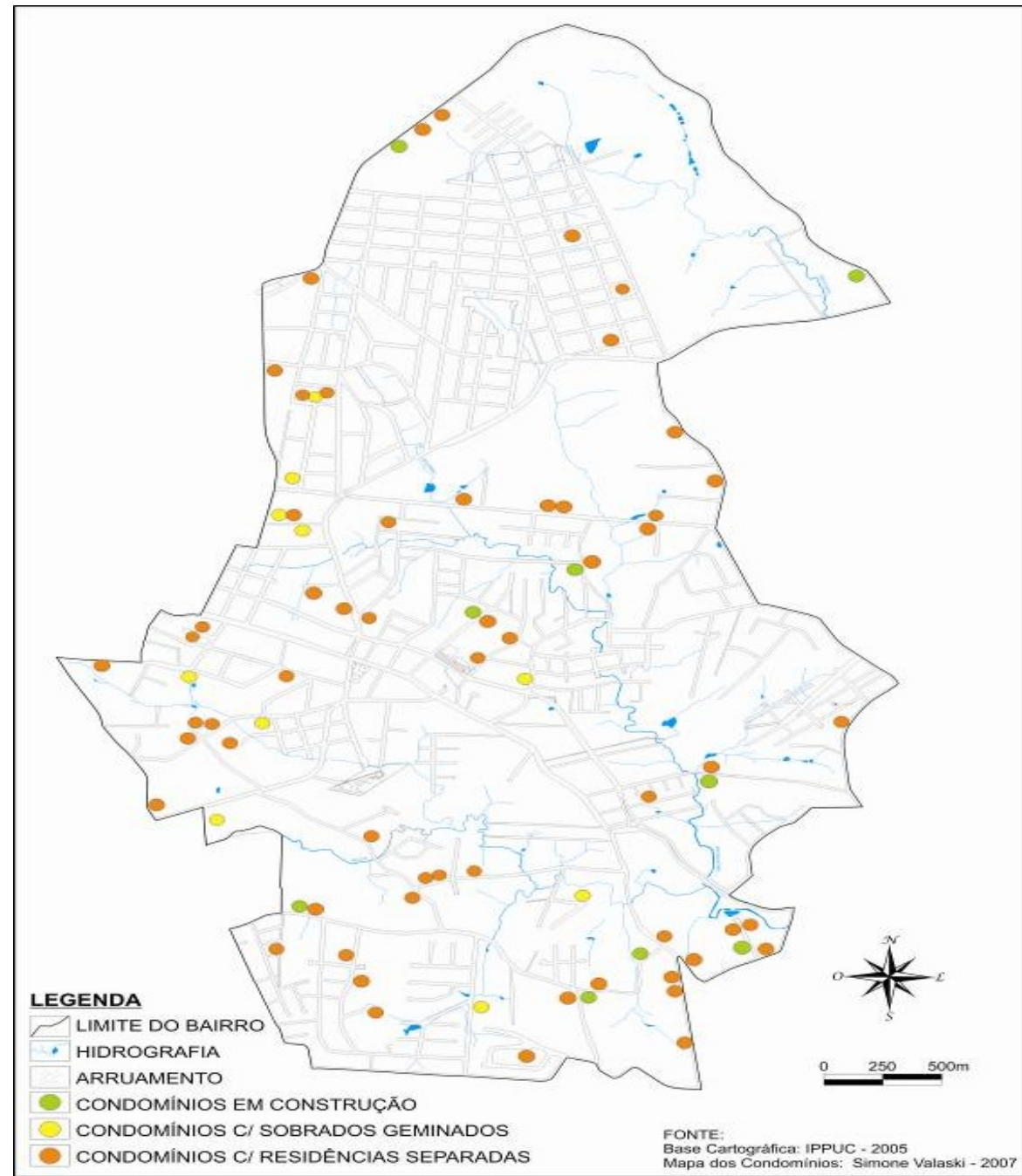

Figura 5 - Localização dos condomínios no Bairro Santa Felicidade 


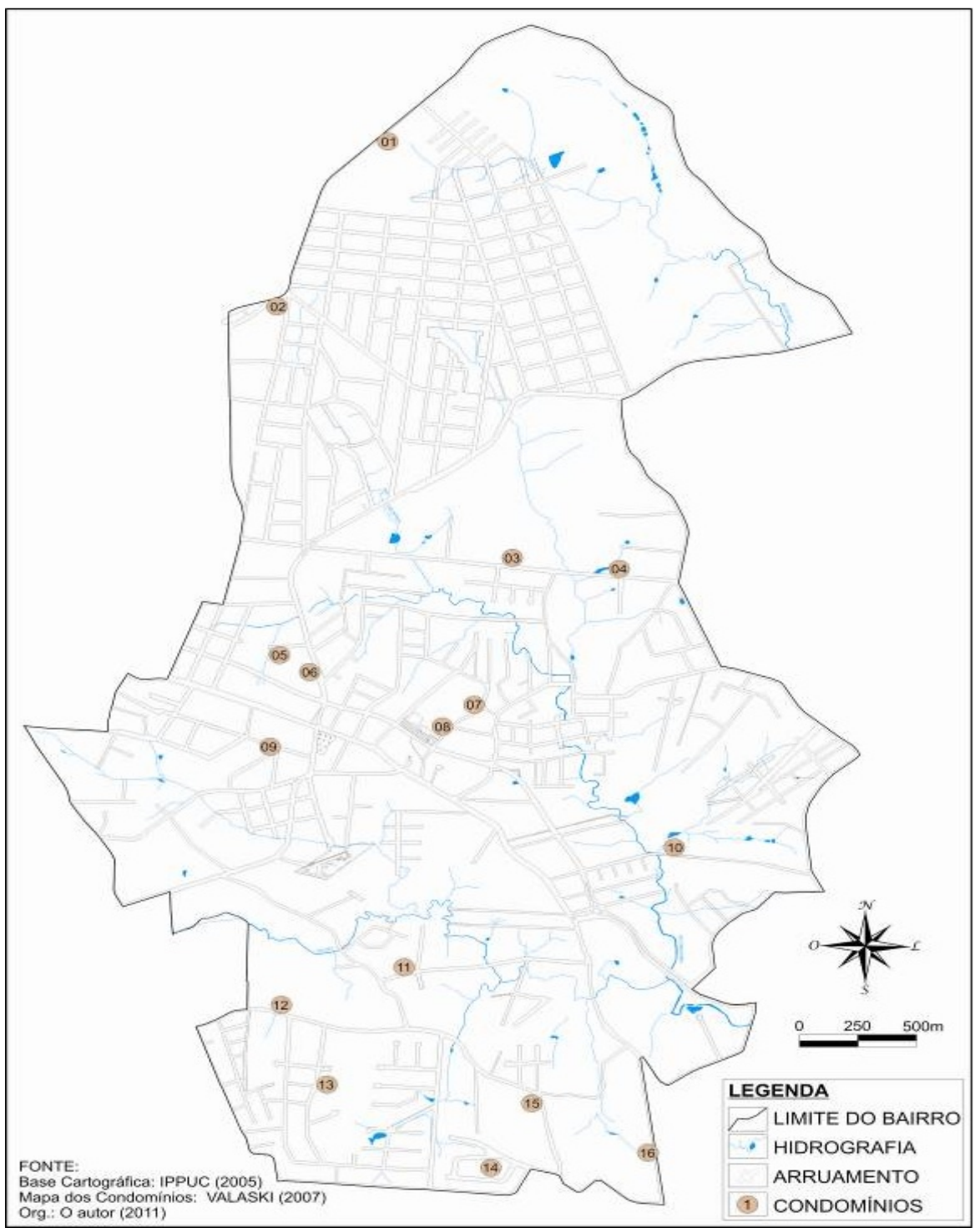

Figura 6 - localização dos condomínios selecionados

\section{Resultados e Discussão}

Os valores resultantes do cálculo de cobertura vegetal arbórea (C.V.A), assim como a avaliação final e a descrição dos condomínios foram organizados em uma tabela (TABELA 1).

\begin{tabular}{|c|c|c|c|}
\hline CONDOMÍNIOS & C.V.A. & AVALIAÇÃO & DESCRIÇÃO \\
\hline 01 & $4 \%$ & NEGATIVA & 01 fragmento isolado \\
\hline 02 & $2 \%$ & NEGATIVA & Indivíduos dispersos \\
\hline 03 & $9 \%$ & NEGATIVA & Indivíduos dispersos \\
\hline 04 & $13 \%$ & NEGATIVA & 02 fragmentos isolados + indivíduos dispersos \\
\hline 05 & $2 \%$ & NEGATIVA & Indivíduos dispersos \\
\hline 06 & $1 \%$ & NEGATIVA & Indivíduos dispersos \\
\hline 07 & $7 \%$ & NEGATIVA & 01 fragmento isolado + indivíduos dispersos \\
\hline 08 & $1 \%$ & NEGATIVA & Indivíduos dispersos \\
\hline
\end{tabular}

Geografia Ensino \& Pesquisa, v. 16, n.1, p. 103116, jan.jun. 2012

Cobertura vegetal arbórea em condomínios residenciais horizontais do bairro Santa Felicidade - Curitiba/PR 


\begin{tabular}{|c|c|c|c|}
\hline 09 & $7 \%$ & NEGATIVA & Indivíduos dispersos \\
\hline 10 & $26 \%$ & POSITIVA & 02 fragmentos isolados (19de.1peq)+ indivíduos dispersos \\
\hline 11 & $2 \%$ & NEGATIVA & Indivíduos dispersos \\
\hline 12 & $19 \%$ & NEGATIVA & 03 fragmentos isolados + indivíduos dispersos \\
\hline 13 & $6 \%$ & NEGATIVA & 01 fragmento isolado + indivíduos dispersos \\
\hline 14 & $20 \%$ & MEDIANA & 02 fragmentos isolados + indivíduos dispersos \\
\hline 15 & $1 \%$ & NEGATIVA & Indivíduos dispersos \\
\hline 16 & $29 \%$ & POSITIVA & Fragmentos interligados + indivíduos dispersos \\
\hline
\end{tabular}

Tabela 1 - Resultado da avaliação da cobertura vegetal arbórea dos condomínios estudados Fonte: $O$ autor (2011)

Dos dezesseis condomínios avaliados apenas dois tiveram uma avaliação positiva: os condomínios 10 e 16, que tiveram como resultado, respectivamente, 26\% e 29\% de cobertura vegetal arbórea. O condomínio 14 teve como resultado uma avaliação mediana, com 20\% de C.V.A. Os treze condomínios restantes tiveram uma avaliação negativa, sendo que a maioria deles com valores muito inferiores ao limite de $20 \%$ estipulado para esta classificação. Os maiores valores encontrados neste grupo foram 13\% e 19\%, para os condomínios 04 e 12 , respectivamente. O menor percentual encontrado foi de 1\%, para os condomínios 06, 08 e 15 .

Esses resultados apontam uma diminuição gradativa da cobertura vegetal total do bairro, à medida que ocorre a implantação de condomínios. Para se manter a média, cada condomínio deveria conservar 0 valor de $31 \%$ de cobertura vegetal arbórea, conforme 0 encontrado por Moura e Nucci (2010) para todo o bairro, já que quase a totalidade dessa cobertura vegetal se encontrava em espaços de uso privado.

Dos valores encontrados neste artigo, apenas um condomínio (16), com 29\% de cobertura vegetal arbórea, aproxima-se do valor encontrado para todo o bairro.

Apesar de não existir um índice ideal de cobertura vegetal em áreas urbanizadas, é possível comparar os resultados encontrados com as proposições feitas por alguns autores apresentados no referencial teórico.

Para Oke (1973 apud LOMBARDO, 1985) um índice de cobertura vegetal na faixa de 30\% seria o recomendável para proporcionar um adequado balanço térmico em áreas urbanas, e que um percentual de arborização inferior a 5\% determina características semelhantes à de um deserto.

Com base nestes percentuais, os resultados encontrados mostram que apenas dois condomínios aproximam-se da faixa de 30\%: 10 (26\%) e 16 (29\%). Entretanto, é importante ressaltar que a proposta de $30 \%$ refere-se à cobertura vegetal, na qual todos os estratos vegetacionais estão incluídos (arbóreo arbustivo e herbáceo). Deste modo, também pode ser incluído nesta sugestão de índice o condomínio 14, com 20\% de cobertura vegetal arbórea.

Quanto ao valor inferior a 5\% de arborização, os resultados obtidos nos condomínios avaliados mostram que sete deles podem ser classificados como desertos florísticos: 01 (4\%),

Geografia Ensino \& Pesquisa, v. 16, n.1, p. 103 116, jan.jun. 2012

Cobertura vegetal arbórea em condomínios residenciais horizontais do bairro Santa Felicidade - Curitiba/PR ISSN 2236- 4994 02 (2\%า), 05 (2\%), 06 (1\%), 08 (1\%), 11 (2\%) e $15(1 \%)$.

Para Sukopp e Werner (1991) 33\% da área central da cidade deveriam ser permeáveis, não edificados e cobertos por vegetação.

Esta proposta assemelha-se às sugestões de Oke (1973), tanto em referência ao valor (30\%) quanto em consideração à cobertura vegetal, e não apenas à cobertura vegetal arbórea. 
Assim, a comparação deste índice com os resultados encontrados são os mesmos apresentados na comparação com a proposição de Oke (1973).

Attwell (2000) apresenta uma meta de 50\% de cobertura vegetal para a cidade de Munique, na Alemanha, para as áreas residenciais de baixa verticalização, sendo que $25 \%$ devem ser de cobertura vegetal arbórea e arbustiva.

Dois condomínios podem ser colocados nesta classificação: os condomínios 10 (26\%) e 16 (29\%), sendo que o segundo apresenta um valor superior aos 25\% sugerido. Entretanto, é importante destacar, como aconteceu nas comparações anteriores, que o índice proposto em Attwell (2000) considera 25\% de cobertura vegetal nos estratos arbóreo e arbustivo. Deste modo, também é possível incluir aqui o condomínio 14 (20\%), já que os resultados apresentam a cobertura vegetal no estrato arbóreo.

$\mathrm{Na}$ figura 7 estão representadas as imagens de satélite com 0 contorno e a cobertura vegetal arbórea de quatro condomínios.

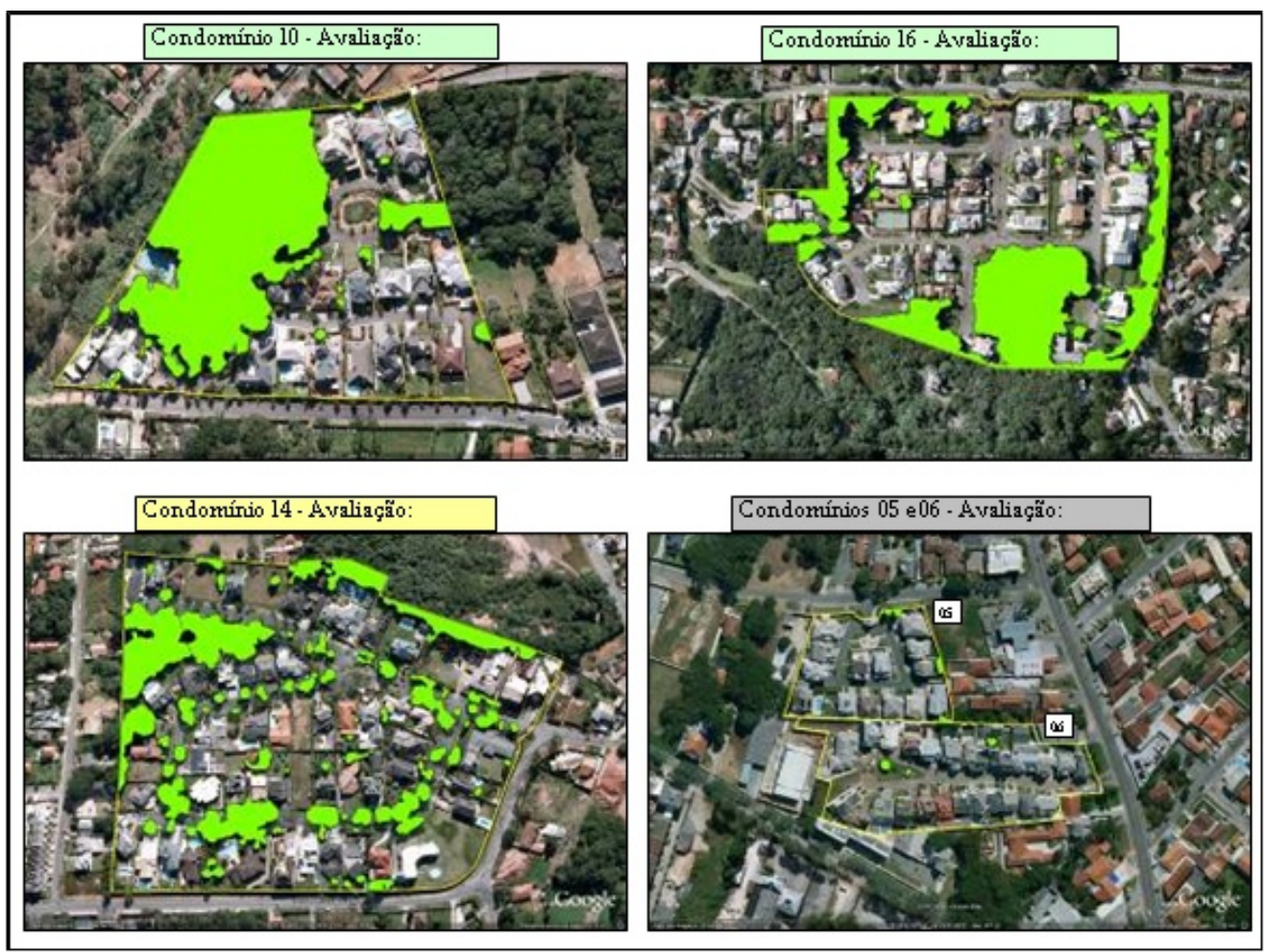

Figura 7 - Exemplos de distribuição da cobertura vegetal arbórea dos condomínios Fonte: 0 autor (2011)

\section{Conclusões}

Os condomínios residenciais horizontais configuram-se como uma opção de moradia que vem sendo cada vez mais freqüente nas cidades brasileiras. De maneira geral, um dos motivos que estimula a busca por estes empreendimentos é a possibilidade de maior contato dos seus moradores com elementos da natureza. Este aspecto é bastante explorado pelas construtoras no momento da venda dos seus empreendimentos.

Entretanto, os resultados apresentados neste trabalho mostraram que nem sempre a propaganda condiz com a realidade. Dos dezesseis condomínios analisados, apenas dois

Geografia Ensino \& Pesquisa, v. 16, n.1, p. 103116, jan.jjun. 2012

Cobertura vegetal arbórea em condomínios residenciais horizontais do bairro Santa Felicidade - Curitiba/PR 
tiveram um resultado considerado satisfatório. Os demais apresentaram pequenas quantidades de vegetação arbórea, muito aquém dos valores propostos por Valaski (2008) e outros e daquilo que é oferecido pela propaganda.

Apesar da inexistência de um índice ideal de vegetação arbórea para as áreas urbanas, a validade da metodologia utilizada neste artigo foi corroborada por outros autores, que sugerem alguns valores que podem ser considerados satisfatórios para que os benefícios da arborização possam melhorar a ambiência urbana. $E$ isto ficou demonstrado nas comparações feitas entre os resultados encontrados e os índices sugeridos por outros autores.

A vegetação, especialmente a de porte arbóreo, traz inúmeros benefícios para a qualidade ambiental urbana. Com a expansão da construção dos condomínios residenciais horizontais no bairro, as áreas antes ocupadas por fragmentos de vegetação diminuem drasticamente, sendo substituídos pelas edificações.

Pode-se concluir, portanto, que o poder público não está trabalhando para a proteção e para 0 aumento da cobertura vegetal do bairro, já que menos de $1 \%$ da cobertura vegetal se encontra em espaços de uso público, e que também não se consegue impedir a diminuição paulatina da cobertura vegetal localizada nos espaços de uso privado, considerando que com a implantação de condomínios, o que se conserva de vegetação arbórea é inferior à média do bairro.

Desta forma, conclui-se que a maioria dos empreendimentos estudados não se configura como elementos do meio urbano que contribuam positivamente para a qualidade ambiental do bairro.

\section{Referências}

ALBUQUERQUE, R.; IVAN, M.; MARTINI, L.F. Viver a vida Alphaville: Alphaville 30 anos. Săo Paulo: M.I.Marketing, 2003.

ATTWELL, K. Urban land resources and urban planting - case studies from Denmark. Landscape and Urban Planning, n.52, p. 145-163, 2000. Disponível em: <www.elsevier.com/locate/landurbplan>. Acesso em: 20/05/2011.

BARTON, H.; TSOUROU, C. Health urban planning. A WHO guide to planning for people. Londres: Spon Press (em nome da Organização Mundial da Saúde - WHO), 2000.

BECKER, D. Condomínios horizontais fechados: avaliação de desempenho interno e impacto físico espacial no espaço urbano. 308p. Dissertação (Mestrado em Planejamento Urbano e Regional) - Faculdade de Arquitetura e Urbanismo, Universidade Federal do Rio Grande do Sul, Porto Alegre, 2005.

CALDEIRA, T. P. R Cidade de muros: crime, segregação e cidadania em São Paulo. São Paulo: Edusp, 2000.

DACANAL, C. Acesso Restrito: reflexões sobre a qualidade ambiental percebida por habitantes de condomínios horizontais. 192p. Dissertação (Mestrado em Geografia - Área de Concentração em Organização do Espaço) - Instituto de Geociências e Ciências Exatas, Universidade Estadual Paulista, Rio Claro, 2004.

Geografia Ensino \& Pesquisa, v. 16, n.1, p. 103 116, jan.jun. 2012

Cobertura vegetal arbórea em condomínios residenciais horizontais do bairro Santa Felicidade - Curitiba/PR
DELICATO, C.T. Faces de Marília: a moradia em um condomínio. 124p. Dissertação (Mestrado em Ciências Sociais) - Faculdade de Filosofia e Ciências, Universidade Estadual Paulista "Júlio de Mesquita Filho", Marília, 2004.

HOUGH, M. Naturaleza y ciudad. Planificación y procesos ecológicos. Barcelona: Gustavo Gilli, 1998, $315 p$. 
IPPUC - Instituto de Pesquisa e Planejamento Urano de Curitiba. Disponível em http://ippucnet.ippuc.org.br/Bancodedados/Curitibaemdados/anexos/1975_Histórico

\%20do\%20Bairro\%20Santa\%20Felicidade.pdf. Acesso em 30/01/2011.

JIM, C. Y. - Tree-canopy characteristics and urban development in Hong Kong. Geographical Review, n. 2, v. 79, New York, American Geographical Society, p. 210- 255,1989.

LOMBARDO, M. A. Ilha de calor nas metrópoles: o exemplo de São Paulo. São Paulo: Hucitec, 1985.

MASCARÓ, L. E. Ambiência urbana. Porto Alegre: Sagra - D.C. Luzzatto Ed., 1996.

MOURA, A. R.; NUCCl, J. C. Classificação da cobertura vegetal do bairro de Santa Felicidade, Curitiba-PR. In: João Carlos Nucci (Org.) Planejamento da Paisagem como subsídio para a participação popular no desenvolvimento urbano. Estudo aplicado ao bairro de Santa Felicidade - Curitiba/PR. Curitiba: LABS/DGEOG/UFPR, 2010. Disponível em: <www.geografia.ufpr.br/laboratorios/labs>. Acesso em: 02 ago 2011.

NUCCI, J. C. Qualidade ambiental e adensamento urbano. São Paulo: Humanitas/Fapesp, 2001.

$\mathrm{NUCCl}$, J. C. Qualidade Ambiental e Adensamento Urbano: um estudo de ecologia e planejamento da paisagem aplicado ao distrito de Santa Cecília (MSP). Curitiba: Edição do autor (ISBN 978-85-908251-0-4), 2008 ( $2^{\mathrm{a}}$ ed.). 142p. Disponível em <www.geografia.ufpr.br/laboratorios/labs/?pg=publicacoes-php>. Acesso em: 20 jun 2011.

O'NEILL, M.M.V.C. Condomínios exclusivos: um estudo de caso. In: Revista Brasileira de Geografia. Rio de Janeiro: IBGE,1986. $n^{0}$ 48, p.63-81.

SBAU - Sociedade Brasileira de Arborização Urbana. Carta de Bento Gonçalves. XIV Congresso Brasileiro de Arborização Urbana. Disponível em: <www.sbau.org.br>. Acesso em: 15 fevereiro 2010.

SILVA, R. F. da. Condomínios horizontais fechados em Goiânia. Um caso: Privê Atlântico. Dissertação de mestrado. Universidade Federal de Goiás. 2003. 163p.

SUKOPP, H.; WERNER, P. Naturaleza em las ciudades. Madrid: Ministério de Obras Públicas y Transportes (MOPT), 1991.

VALASKI, S. Avaliação da qualidade ambiental em condomínios residenciais horizontais com base nos princípios do Planejamento da Paisagem. Estudo de caso: bairro Santa Felicidade - Curitiba/Pr. 153p. Dissertação (Mestrado em Geografia) - Setor de Ciências da Terra, Universidade Federal do Paraná, 2008.

\section{Correspondência}

Simone Valaski - Departamento de Geografia - Universidade Federal do Paraná. Av. Cel. Francisco Hoffman dos Santos, 100. Jardim das Américas. 81531-980 - Curitiba, PR - Brasil

E-mail: simonevalaski@ig.com.br

Recebido em 25 de março de 2012.

Revisado em 26 de abril de 2012.

Aprovado em 21 de maio de 2012.

Geografia Ensino \& Pesquisa, v. 16, n.1, p. 103116, jan.jjun. 2012

Cobertura vegetal arbórea em condomínios residenciais horizontais do bairro Santa Felicidade - Curitiba/PR

ISSN 2236- 4994 